\title{
Comparing Advertising Effectiveness: Successful versus Attractive Male Spokesperson: An Abstract
}

\author{
Feray Adiguzel and Carmela Donato
}

\begin{abstract}
According to evolutionary psychology studies (e.g., Buss 1989), women select partners mainly based on their financial prosperity, highlighting the importance of financial success among males. In that sense, Gulas and McKeage (2000) found that exposure to advertising containing idealized images of financially successful males reduced males' level of self-esteem. However, they investigated only negative effects in terms of self-perceptions, but not advertising effectiveness, and more importantly, they did not include in their analysis attractiveness.

The present research aims to cover this gap, focusing on comparison of marketing effects of using successful versus attractive male spokesperson in advertising on male and female consumers. Among two experimental studies, we demonstrated that when a male consumer compares himself to an attractive male spokesperson, the attitude toward the ad is positive; but when he compares himself to a successful male spokesperson, the attitude toward the ad is negative. Thus, men who compare themselves with a successful spokesperson show a similar derogation effect as women who compare themselves with an attractive model. Additionally, the use of a successful male spokesperson results in reduced purchase intention only on males due to negative effect created by jealousy; the negative effect disappears when also female receivers are considered.
\end{abstract}

References Available Upon Request

\footnotetext{
F. Adiguzel $(\bowtie) \cdot C$. Donato

LUISS Guido Carli University, Rome, Italy

e-mail: fadiguzel@luiss.it; donatoc@luiss.it
} 